* Bacharel em Direito pela Universidade de Caxias do Sul (UCS). Bacharelando em Engenharia Geológica (UFPEL)

** Pós-doutor em Direito (UFRGS). Doutor e Mestre em Direito (UFRGS). Bacharel em Direito (UNISINOS). Professor Efetivo da Universidade Regional de Blumenau (FURB). Vice-líder do grupo de pesquisa $\mathrm{CNPq} /$ FURB 'Direitos Fundamentais, Cidadania e Justiça'.

\section{DIREITO HUMANO À MORADIA E REGULARIZAÇÃO FUNDIÁRIA}

\author{
HUMAN RIGHT TO DWELLING AND LAND \\ REGULARIZATION
}

Israel Bachi*

Leonardo da Rocha de Souza**

Como citar: BACHI, Israel; SOUZA, Leonardo da Rocha. DIREITO HUMANO À MORADIA E REGULARIZAÇÃO FUNDIÁRIA. Revista do Instituto de Direito Constitucional e Cidadania - IDCC, Londrina, v. 4, n. 1, p 163-175, ago, 2019. ISSN: 2596-0075.

https://doi.org/10.48159/revistadoidcc.v4n1.bachi.souza

Resumo: $\mathrm{O}$ direito à moradia e o direito à cidade são abordados, neste artigo, como garantias fundamentais para a efetivação da plena cidadania. Para isso, estuda-se a regularização fundiária com interesse social como medida possível para a efetivação de políticas públicas voltadas para essa área. Como resultado, percebe-se que, apesar da previsão legal da regularização fundiária, o direito à moradia e à cidade sustentável continuam sendo de difícil realização, pois a existência de leis como o Estatuto da Cidade, Minha Casa Minha Vida e Regularização Fundiária Rural e Urbana (Reurb) não têm impedido a multiplicação das ocupações irregulares. Além disso, percebe-se que há a necessidade de, após a regularização fundiária, realizarse um levantamento jurídico, econômico e social que permita ampliar os recursos públicos, realizando-se uma gestão social para valorização das terras para torná-las mais sustentáveis e urbanizando-as para dar dignidade aos moradores, e evitando-se a gentrificação. Utiliza-se o método de procedimento tipológico, com uma abordagem hermenêutica e um delineamento de pesquisa qualitativa bibliográfica.

Palavras-chaves: Moradia. Direito à Cidade. Cidadania. Cultura Política. Políticas Públicas.

Abstract: The right to housing and the right to the city are approached in this article as fundamental guarantees for the realization of full citizenship. For this, the land regularization 
with social interest is studied as a possible measure for the implementation of public policies directed to this area. As a result, it is perceived that, despite the legal prediction of land regularization, the right to housing and the sustainable city continue to be difficult, since the existence of laws such as the City Statute, My House My Life and Rural Land Regularization and Urban (Reurb) have not prevented the multiplication of irregular occupations. In addition, it is perceived that there is a need, after land regularization, to carry out a juridical, economic and social survey that allows to increase the public resources, being realized a social management for valorization of the lands to make them more sustainable and urbanizing them to give dignity to the residents, and avoiding gentrification. The methodological procedure is used, with a hermeneutic approach and a qualitative bibliographical research design.

Keywords: Housing. Right to the City. Citizenship. Political Culture. Public policy. 


\section{INTRODUÇÃO}

Diante da necessidade que a Administração Pública tem de garantir o direito à moradia, costuma-se perceber a regularização fundiária como uma forma de proporcionar certa segurança aos vulneráveis, ajustando, urbanizando e harmonizando ambientes de ocupação irregular. A realidade das ocupações urbanas gera a necessidade de uma atuação da Administração Pública na busca de soluções para o problema da falta de moradia, o que vem acompanhado da ausência de um projeto de cidade nessas áreas que historicamente foram marginalizadas.

Como o direito à moradia e o direito à cidade são direitos humanos e garantias fundamentais necessários para a efetivação da plena cidadania nessas áreas, o Poder Público tem realizado projetos de Regularização Fundiária com Interesse Social como medidas para a efetivação de políticas públicas voltadas para esse espaço renegado e ausente na esfera pública.

Assim, o objetivo deste estudo é realizar um breve levantamento dos instrumentos que estão à disposição da Administração Pública para realizar a Regularização Fundiária Urbana em áreas de Interesse social, especificamente as favelas. E, considerando a distribuição desigual das benesses de infra-estruturas e serviços disponíveis, apontar quais os instrumentos da Administração Pública deveriam transformá-los em equânimes (art. $2^{\circ}$, incisos IX e XI do Estatuto da Cidade).

Em relação à metodologia científica adotada, optou-se por uma abordagem epistemológica hermenêutico-dialética, já que se pretende trabalhar o contexto da previsão legal sobre regularização fundiária, partindo-se para a crítica da sua ineficácia, valorizando, portanto, "processos de criação de consensos e contradições" (HENRIQUES; MEDEIROS, 2017, p. 9394). Esta pesquisa tem um delineamento qualitativo, por meio da pesquisa bibliográfica, pois está focalizada em "selecionar informações bibliográficas para explicar o problema objeto da investigação" (HENRIQUES; MEDEIROS, 2017, p. 107). O método de procedimento escolhido é o tipológico, que "estabelecido por Max Weber, consiste em criar modelos ideais, construídos com base em elementos fundamentais de um fenômeno" (HENRIQUES; MEDEIROS, 2017, p. 45), o que, para os fins deste artigo, significa criar um modelo ideal de tratamento das ocupações irregulares.

\section{DIREITO À MORADIA}

Para falar em direito à moradia, segue-se a estrutura proposta por D'Ambrosio (2013). Num primeiro momento, usa traços gerais para falar de moradia, diferenciando-a do conceito de habitação; em seguida, utiliza Tratados e Convenções internacionais sobre o assunto; após, trata-o como um direito fundamental social, utilizando-se de conceitos e disposições constitucionais.

A moradia, para Souza (2013, p. 40), é, antes de tudo, um bem com personalidade própria, de proteção constitucional e civil. Portanto, um bem de caráter irrenunciável da pessoa natural, que independe de sua vontade e é indisponível. É, ainda, um objeto de direito protegido universalmente, tal qual os bens extrapatrimoniais de imagem, honra e intimidade. $\mathrm{O}$ bem moradia 
está ligado à pessoa e, por estar relacionado a lar, independe de objeto físico para sua existência e proteção jurídica. “Atualmente, é uma situação de direito reconhecida pelo ordenamento jurídico, é uma qualificação legal reconhecida como direito inerente a todo ser humano, notadamente, em face da natureza de direito essencial referente à personalidade humana". Assim, a moradia não guarda, necessariamente, relação com o direito à propriedade (o imóvel), podendo ser exercido independentemente dele.

Em linhas gerais, D’Ambrosio (2013,p. 11) reforça esse aspecto de essencialidade da moradia como condição à dignidade da vida humana. É necessária a inviolabilidade da moradia para tal dignidade, o que inclui assegurar um local seguro, digno e salubre para o indivíduo e sua família "se recolherem após um dia de trabalho, no qual seja possível dormir, higienizar-se, preparar alimentos, conviver com a família, participar ativamente da educação dos filhos, construir projetos de vida e gozar de privacidade de forma mais plena".

Souza (2013, p. 40), quando conceitua a habitação, traça a relação direta da pessoa com o bem, delimitando-a num dado tempo, isto é, de caráter acidental e sem o ânimo da permanência. Já a moradia, por ser uma tutela subjetiva, axiologicamente ligada à pessoa, exige uma prestação Estatal, um dever para atender seu pleno exercício. Exemplificando: a habitação instrumentaliza a moradia, pois há casos em que se faz necessário retirar o direito à habitação, para atender o direito à moradia, como quando determinadas pessoas ocupam áreas impróprias à fixação domiciliar e o Estado, ciente, deve intervir para dar plenitude a esse último direito.

Ainda, D’Ambrósio (2013) chama atenção para as diretrizes internacionais pertinentes ao assunto da moradia digna. Romanelli (2007, p. 41) entende que o maior período de progresso sobre os fundamentos legais internacionais desse direito foram os anos 90, pois foi somente a partir desse período que foi incorporado aos ordenamentos nacionais. Segundo o autor, a previsão normativa teve início na Declaração Universal dos Direitos Humanos de 1948 que, em seu artigo XXV, item $1^{1}$, já reconhecia o direito à moradia adequada. Após, o assunto foi tratado no Pacto Internacional de Direitos Sociais, Econômicos e Culturais de 1966 em seu artigo 11², tendo sido ratificado pelo Brasil somente em 24/01/1992.

Souza (2013, p. 62) cita ainda: Convenção Americana de Direitos Humanos Pacto de San José da Costa Rica; Declaração sobre o Direito e Deveres do Homem; a Convenção Relativa ao Estatuto dos Refugiados; Pacto Internacional dos Direitos Civis e Políticos; a Convenção Internacional sobre a Eliminação de todas as Formas de Discriminação Racial; a Convenção sobre os Direitos da Criança, e a Declaração sobre Assentamentos Humanos de Vancouver. Ele entende que ao direito humano à moradia pode-se atribuir a universalidade, a indivisibilidade, a

1 "Toda pessoa tem direito a um padrão de vida capaz de assegurar a si e sua família saúde e bem-estar, inclusive, alimentação, vestuário, habitação, cuidados médicos, e os serviços sociais indispensáveis, e direito à segurança em caso de desemprego, doença, invalidez, viuvez, velhice ou outros casos de perda de meios de subsitência fora de seu controle". Acesso em 10/12/2018, disponível em: <http://www.ohchr.org/EN/UDHR/Documents/UDHR_ Translations/por.pdf $>$

2 "Os Estados partes do presente Pacto reconhecem o direito de toda pessoa a um nível de vida adequado para si próprio e para sua família, inclusive à alimentação, vestimenta e moradia adequada, assim como tomarão medidas apropriadas para assegurar a consecução desta direito, reconhecendo, nesse sentido, a importância essencial da cooperação internacional fundada no livre consentimento", Acesso em 10/12/2018; disponível em: <http://www. planalto.gov.br/ccivil_03/decreto/1990-1994/d0591.htm> 
interdependência e a interrelação, conforme dispõe o artigo $5^{\circ}$, parte I, da Declaração e Programa de Ação de Viena de 25/06/1993.

Para D'Ambrósio (2013, p. 13), o direito à moradia deve pressupor alguns requisitos inerentes:

i) Segurança legal da posse: a posse deve ser protegida em qualquer uma das suas variadas formas, como locação, acomodação, habitação cooperativa, arrendamento, uso pelo proprietário, habitação de emergência e assentamentos informais. As pessoas devem ter segurança contra os despejos forçados, pressões incomodas e outras ameaças.

ii) Disponibilidade de serviços, materiais, facilidade e infraestrutura: a moradia deve dispor de serviços essenciais para saúde, segurança, conforto e nutrição. As pessoas devem ter acesso a recursos naturais e comuns, água potável, energia para preparo de alimentos, aquecimento e iluminação, facilidades sanitárias, meios de armazenamentos de comida, depósitos de resíduos e de lixo, drenagem do local e serviços de emergência.

iii) Custo acessível: o custo com a moradia deve guardar proporção com níveis de renda, de modo a não ameaçar ou comprometer a satisfação com outras necessidade básicas. Deve haver subsídios públicos e financeiros para atender os incapazes de arcar com esse custo. $\mathrm{O}$ valor dos alugueis deve também ser razoável.

iv) Habitabilidade: a moradia deve ter espaço adequado, boa condição de higiene, garantir a segurança física de seus ocupantes e protegê-los do frio, da humidade, do calor, da chuva, do vento, das ameaças à saúde, dos vetores de doenças e dos riscos estruturais.

v) Acessibilidade: as pessoas devem ter acesso à moradia adequada e deve ser dada prioridade aos grupos desfavorecidos, como idosos, crianças, deficientes físicos, doentes crônicos, doentes terminais, doentes mentais, vítimas de desastres naturais, moradores de áreas de risco, entre outros.

vi) localização: a moradia deve ser localizada em áreas com opção de trabalho, serviço de saúde, escolas, creches e outros serviços públicos. Além disso, a moradia não deve estar em local poluído, nem nas proximidades de fontes de poluição que ameacem a direito à saúde dos habitantes.

vii) Adequação cultural: a moradia deve preservar uma dimensão cultural, que inclui a maneira como ela é construída, os materiais de construção usados e as políticas em que se baseia. Também devem ser asseguradas, facilidades tecnológicas modernas.

Ainda na esfera internacional, destacam-se as Agendas Habitat das Conferências das Nações Unidas para os Assentamentos Humanos e Agenda 21, iniciada com a Rio 92 e concluída em 2002, que foi amplamente aceita e assimilada pelas agendas políticas locais, com foco no equilíbrio social, ambiental e econômico para amenizar as desigualdades sociais e regularizar fundiariamente as áreas e assentamentos informais e os loteamentos irregulares.

Na perspectiva constitucional, o direito à moradia é um dos direitos humanos que foi amplamente protegido pela Carta Magna brasileira. Antes mesmo da inclusão da moradia no art. $6^{\circ}$ da Constituição pela Emenda Constitucional n ${ }^{\circ} 26$ de 14/02/2000 (atendendo orientação 
da Agenda Habitat II), o assunto estava inserido na Constituição Federal no art. $7^{\circ}$, IV; art. 23, IX; arts. 183 e 191. Os dispositivos internacionais (SOUZA, 2013, p. 85) são assimilados conforme os artigos $5^{\circ}, \S 3^{\circ}$ da Constituição Federal, atendendo também ao disposto no artigo $4^{\circ}$, II, assim recebidos conforme critérios que a própria Constituição lhe condiciona.

Com a superveniência da inclusão da moradia no art. $6^{\circ}$ da Constituição Federal, esse direito passou a ser duplamente fundamentado: "hoje expressamente no rol dos direitos sociais do artigo $6^{\circ}$ da Constituição Federal de 1988, e, sob o aspecto material, refere-se a um bem jurídico de maior relevância, indissociável da dignidade da pessoa humana" (D’AmBrósio, 2013, p. 21.)

Rangel e Silva (2009, p. 66) defendem uma Teoria do Patrimônio Mínimo, que é uma garantia ao indivíduo para lhe assegurar a dignidade, dando novos ares às aplicações do Direito Civil, concebido pelo caráter despatrimonialista e repersonalizado em oposição à corrente liberal de proteção da propriedade privada. Nessa Teoria, o pressuposto básico é que todos devem ter um patrimônio mínimo essencial à sua dignidade. A garantia de um mínimo patrimonial é essencial como uma forma de defesa em um sistema capitalista, no qual esse mínimo é também, consequentemente, garantia significativa do desenvolvimento para uma vida digna. Tal teoria, em consonância com o direito à moradia, "constitucionalmente consignado no art. $6^{\circ}$ da Constituição Federal de 1988, pressupõe que a moradia do ser humano, onde ele habita com a sua família, deve ser protegida".

Relegado ao esquecimento, o direito à moradia é fundamental na emancipação digna do indivíduo como ente integrante da cidade, não como mero espectador ou somente um ficto cidadão. Tal direito é essencial para a efetivação do projeto de vida democrático previsto na Carta Política de 1988. (RANGEL; SILVA, 2009, p. 68). Por isso é tão necessário que a Administração Pública utilize os instrumentos que tem à sua disposição para atender esse direito, o que será visto no próximo tópico com ênfase na regularização fundiária urbana com interesse social.

\section{REGULARIZAÇÃO FUNDIÁRIA URBANA COM INTERESSE SOCIAL}

A regularização fundiária urbana com interesse social é um instituto recente, que foi contemplado no Capítulo III da Lei Federal 11.977 de 2009 (Lei da Minha Casa Minha Vida) alterado pela Lei $n^{\circ} 13.465$, de 11 de julho de 2017, que passou a dispor sobre a regularização fundiária rural e urbana, em resposta às diretrizes constitucionais e às estabelecidas no Estatuto das Cidades de 2001 que concentram e, pela primeira vez, estabelecem critérios administrativos e paradigmas à solução dos problemas da efêmera posse de terras dessas áreas ocupadas irregularmente.

A análise realizada neste tópico segue a linha traçada pelo Ministério das Cidades em Cartilha (BRASIL, 2010) fornecida às prefeituras e demais entidades envolvidas com a regularização fundiária em bairros populares. Desse material seleciona-se a parte relacionada aos vulneráveis e ao interesse social.

A regularização fundiária é importante pois traz à legalidade uma considerável 
parcela da população que, historicamente ${ }^{3}$, não teve acesso à moradia digna, muito menos o direito à cidade sustentável (a ser promovido pela Administração Pública). É possível associála diretamente ao exercício de cidadania. Morar irregularmente significa estar em condição de insegurança permanente, "por esse motivo, além de um direito social, podemos dizer que a moradia regular é condição para a realização integral de outros direitos constitucionais, como o trabalho, o lazer, a educação e a saúde." (BRASIL, 2010, p.8).

Nas favelas, a ocupação se dá por assentamentos precários que não atendem aos padrões urbanísticos ambientais legalmente padronizados, constituindo, tanto social como ambientalmente, impactos negativos ao restante do tecido social. Outro ponto importante que a Cartilha menciona, é um interessante estudo de Maurício Moura, relacionando as ocupações irregulares com o aumento da jornada de trabalho, da renda familiar e, ainda, diminuição do trabalho infantil (BRASIL, 2010, p.8).

Por analogia, a regularização fundiária foi implementada pelo poder público com a mesma intenção da Portaria $n^{\circ} 1.028$, de $1^{\circ}$ de julho de 2005 que regulou a política de redução de dano à saúde pública dos usuários de drogas, aceitando-os como um problema a ser solucionado e, após, interferir com medidas tais que atenuam e produzam efeitos benéficos, sem forçar um padrão ilusório que não corresponde à realidade do local.

Romanelli (2007, p. 103-104) expõe algumas características fundamentais:

Os programas de regularização têm uma natureza essencialmente curativa e não podem ser dissociados de um conjunto mais amplo de políticas públicas, diretrizes de planejamento e estratégias de gestão urbana destinada a reverter o atual padrão excludente de crescimento urbano. Por outro lado, é preciso ampliar o acesso ao mercado formal a uma parcela mais ampla da sociedade, sobretudo, os grupos de renda média-baixa, ao lado oferta de subsídios públicos para as faixas da menor renda. Por outro lado, é preciso rever os modelos urbanísticos que têm sido utilizados. De forma a adapta-los à realidades sócio-económicas e á limitada capacidade de ação institucional das agendas públicas. Nesse contexto, as políticas de regularização fundiária não podem ser formuladas de maneira isolada e necessitam ser combinadas com outras políticas públicas preventivas para quebrar o ciclo de exclusão que tem gerado a informalidade, Isso requer intervenção direta e investimentos públicos, sobretudo, por parte dos municípios, para produzir opções de moradia, democratizar o acesso à terra e promover uma reforma urbana ampla. Regularizar sem interromper o ciclo de produção de irregularidades, além de renovar o sofrimento da população, provoca a multiplicação permanente da demanda por recursos públicos.

3 “A origem das causas que levam à ocupação irregular por população de baixa renda é econômica: em um país que concentra renda, com corrente migratória rural para o território urbano (baseada na miragem de emprego, melhores condições de vida, acesso à educação e serviços de saúde, dentre outros privilégios da vida nas cidades), a forma de garantir moradia acaba sendo a ocupação irregular, individualmente ou em grupos organizados. As áreas são ocupadas de forma precária, e nelas pululam autoconstruções ocupando morros, córregos, áreas de mananciais; palafitas são erguidas por sobre fétidos cursos d'água, e em áreas de risco; outras maneiras de ocupação irregular estão difundidas e disfarçadas no tecido urbano, como os cortiços. A população a ocupar essas áreas tem contingentes com alguma renda, ou mesmo assalariados, mas ainda à margem do mercado urbano formal”. (PIOLI; ROSSIN, 2006, p.46). 
Somente na década de 60 os efeitos nocivos da urbanização puderam ser “sentidos" pela administração pública. Na década 1970 foi o período que se iniciou a previsão legal sobre o assunto com a Lei Federal do Parcelamento de Solos (Lei n 6.766 de 1979) que não conseguiu resolver nem remediar a crescente vinda de pessoas às cidades. Na década seguinte, houve a incorporação do capítulo sobre as políticas urbanas na Constituição Federal de 1988. Nos anos 90 finalmente houve alteração na Lei de Parcelamento do Solo, dando tratamento especial aos assentamentos populares regularizados no âmbito de ações públicas locais. Já nos anos 2000 diversas normas foram promulgadas, dentre as quais se destacam:

- Em 2001, aprovação do Estatuto da Cidade (Lei Federal nº 10.257/01) pelo Congresso Nacional, e edição da Medida Provisória $n^{0}$ 2.220, que disciplinou a Concessão de uso especial para fins de moradia de imóveis públicos ocupados; - 2003, criação do Ministério das Cidades e instituição da Política Nacional de Regularização Fundiária;

- 2004, aprovação da Lei Federal $n^{0}$ 10.931, que estabelece a gratuidade do primeiro registro decorrente da regularização fundiária;

- 2007, aprovação da Lei Federal $n^{0}$ 11.481, que define mecanismos para a regularização fundiária em terras da União; e, finalmente,

- em 2009 aprovação da Lei Federal n ${ }^{\circ}$ 11.952, que define mecanismos para a regularização fundiária em terras da União na Amazônia Legal e de Lei Federal $n^{\circ}$ 11.977, que dispõe sobre o Programa Minha Casa, Minha Vida e dedica um capítulo à regularização fundiária de assentamentos informais urbanos (BRASIL, 2010, p. 7).

Na sequência, surgiu a Lei n 13.465 , de 11 de julho de 2017, que também passou a dispor sobre a regularização fundiária rural e urbana.

$\mathrm{O}$ artigo $2^{\circ}$, incisos XIV e XV do Estatuto das Cidades, traduz a proposta do legislador para a realização da regularização fundiária:

Art. $2^{\circ}$. A política urbana tem por objetivo ordenar o pleno desenvolvimento das funções sociais da cidade e da propriedade urbana, mediante as seguintes diretrizes gerais:

XIV - regularização fundiária e urbanização de áreas ocupadas por população de baixa renda mediante o estabelecimento de normas especiais de urbanização, uso e ocupação do solo e edificação, consideradas a situação socioeconômica da população e as normas ambientais;

$\mathrm{XV}$ - simplificação da legislação de parcelamento, uso e ocupação do solo e das normas edilícias, com vistas a permitir a redução dos custos e o aumento da oferta dos lotes e unidades habitacionais.

E o artigo 46 da Lei 11.977/09 assim conceituava a Regularização Fundiária :

Art. 46. A regularização fundiária consiste no conjunto de medidas jurídicas, urbanísticas, ambientais e sociais que visam à regularização de assentamentos 
irregulares e à titulação de seus ocupantes, de modo a garantir o direito social à moradia, o pleno desenvolvimento das funções sociais da propriedade urbana e o direito ao meio ambiente ecologicamente equilibrado.

Esse artigo foi revogado pela Lei $\mathrm{n}^{\mathrm{0}} 13.465$, de 11 de julho de 2017, passando a dispor sobre a matéria da seguinte forma:

Art. $9^{\circ}$ Ficam instituídas no território nacional normas gerais e procedimentos aplicáveis à Regularização Fundiária Urbana (Reurb), a qual abrange medidas jurídicas, urbanísticas, ambientais e sociais destinadas à incorporação dos núcleos urbanos informais ao ordenamento territorial urbano e à titulação de seus ocupantes.

$[\ldots]$

Art. 13. A Reurb compreende duas modalidades:

I - Reurb de Interesse Social (Reurb-S) - regularização fundiária aplicável aos núcleos urbanos informais ocupados predominantemente por população de baixa renda, assim declarados em ato do Poder Executivo municipal; e

II - Reurb de Interesse Específico (Reurb-E) - regularização fundiária aplicável aos núcleos urbanos informais ocupados por população não qualificada na hipótese de que trata o inciso I deste artigo.

Assim, no intuito de atender o direito à moradia e à cidade sustentável foram criados instrumentos para a população de baixa renda, procedimentos e requisitos tais que flexibilizam os critérios urbanísticos dessas áreas (CUSTÓDIO, 2002, p. 74). Deve-se buscar uma nova ordem legal urbana, tendo em vista os padrões elitistas impostos por legislações e instrumentos restritivos do estado, fora da realidade econômica da grande parcela da população, "destinados a proteger e reconhecer os direitos da população que vive nos assentamentos precários bem como a sua aplicação mediante sistemas e mecanismos democráticos e participativos." (CUSTÓDIO, 2002, p. 106).

Para a área ocupada ser considerada como de interesse social, antes deve preencher alguns critérios mínimos básicos: os mesmos exigidos para usucapião ou concessão de uso especial para fins de moradia; situar-se em Zonas Especiais de Interesse Social - ZEIS; ou ainda, ser declarada de interesse para a implantação de projetos de regularização fundiária de interesse social, nos casos de áreas da União, dos Estados, do Distrito Federal ou dos Municípios, conforme artigo 47, VII, alíneas "a", "b" e "c" da Lei 11.977/09 (dispositivos revogados e inseridos na Lei $\mathrm{n}^{\circ} 13.465$, de 11 de julho de 2017, que passou a dispor sobre a regularização fundiária rural e urbana).

Assim, pode-se considerar a Regularização Fundiária Urbana com Interesse Social da Lei 13.465/2017 uma ferramenta pertinente à administração pública para atender a população vulnerável, facilitando e promovendo o acesso à moradia e à cidade aos mais pobres. 


\section{O DESAFIO DA GENTRIFICAÇÃO}

Um desafio da nova lei $n^{\circ}$ 13.465/2017 (que não foi vencido pela Lei 11.977/09) é a gentrificação, que "consiste em uma série de melhorias físicas ou materiais e mudanças imateriais - econômicas, sociais e culturais - que ocorrem em alguns centros urbanos antigos, os quais experimentam uma apreciável elevação de seu status” (BATALLER, 2012).

Esta reestruturação dos espaços urbanos (espaços residenciais e comerciais, normalmente em bairros pobres ou degradados), com a substituição por novos empreendimentos, proporcionam tanto a alteração da natureza de determinada localidade como o seu "enobrecimento", e provocam a exclusão da população local, justamente em razão da sua incapacidade financeira em ali permanecer, pois os valores praticados não são mais suportados pela comunidade com menor poder econômico.

$[\ldots]$

Longe de constituir um processo espontâneo e harmônico, a chamada gentrificação aparece simultaneamente como causa e efeito de antagonismos sociais, e responde a processos de desenvolvimento desigual em escala urbana, característicos das últimas décadas, em que o destino de comunidades inteiras é função do modo pelo qual o capital transita em busca das melhores oportunidades de investimento produtivo, e não o contrário. Trata-se de uma ordem de coisas que tem menos a ver com recuperação, revitalização, e reurbanização de espaços do que com o aprofundamento de fissuras sociais, que constituem uma espécie de resíduo de determinadas operações financeiras, tratadas pelo poder público como um fim em si, em detrimento do bem-estar da população em geral, qualquer que seja o conteúdo dessa expressão. (GRAZIANO SOBRINHO; MALINVERNI DA SILVEIRA, 2017, p. 162, 163)

Há uma transformação do espaço urbano; ele se remodela, ocorrendo uma valorização acentuada para o mercado imobiliário, dificultando ou impossibilitando o acesso dos pobres. Essa "revitalização" (embelezamento vazio) é, acima de tudo, um "acúmulo de desapropriação" (HARVEY, 2008, p. 81), pois toma da população de baixa renda suas valiosas terras.

Se uma das medidas principais é assegurar moradia, transformando a posse em propriedade, por outro lado, as medidas de regularização fundiária não têm se mostrado suficientes para estancar a gentrificação. Isto é, em vez de o instituto da regularização fundiária proteger a moradia e melhorar a infraestrutura da favela, acaba por, após as melhorias, expulsar cidadãos pobres que não podem arcar com a supervalorização produzida pela própria regularização. Em resumo: ocorre a apropriação pelo mercado das benesses produzidas pela interferência pública, permitindo que o mercado defina os preços e force, indiretamente, a saída dos mais pobres das áreas revitalizadas. Como alerta Williamson (2013):

a gentrificação, 'remoção branca" ou 'expulsão pelo mercado,' corre o risco de remover muito mais gente de suas casas, modificar favelas em áreas de luxo, tudo sem precisar se legitimar de nenhuma forma. Pois o mercado é visto como 
"natural" e a gentrificação como "inevitável.

O simples título de propriedade já torna o imóvel muitas vezes impossível de adquirir por pessoas mais pobres. Não se trata aqui da mesma gentrificação, isto é, aquela mesma feita pelos mais ricos, e sim um processo atenuado. Porque, na busca pelo lucro, o mercado notou um grande potencial nessas áreas, tendo em vista o número de pessoas envolvidas. Em termos gerais, pela razoável melhora dos últimos anos, os ricos continuam a fazer a mesma gentrificação, mas agora uma camada que "ascendeu" socialmente, gentrifica os mais pobres ainda, ao criarem padrões fictícios de acesso às terras nessas áreas.

O preço da terra pode estar relacionado aos moradores que ali se encontram e àqueles que vêm depois. Assim como pontua Williamson sobre a chegada de moradores "de fora" das comunidades:

O que acontece tradicionalmente com a gentrificação é que com a chegada do primeiro grupo de pessoas "de fora", é desencadeado um processo no mercado local, onde os preços começam a aumentar e a área começa a se valorizar. O primeiro grupo normalmente não é "o problema", pois chegam gostando do local e sem intenção de modificá-lo ou especular. Mas este grupo sem querer notifica o mercado do potencial do local. E o mercado entra em seguida, às vezes devagar e parcialmente, outras vezes rapidamente ou de forma que descaracteriza completamente a área (WILLIAMSON, 2013).

Assim, percebe-se que a regularização fundiária representa uma grande avanço para assegurar a moradia e infraestruturas básicas. Por outro lado, gera outra forma de gentrificação, que pode resultar na "expulsão" das famílias atendidas. Mesmo contraditório, o instituto é de vital importância na promoção do direito à moradia e à cidade aos mais pobres, mas não é suficiente para resolver o problema como um todo, fazendo-se necessárias outras medidas para impedir a apropriação pelo mercado e para promover a redistribuição das benesses das cidades.

\section{CONSIDERAÇÕES FINAIS}

O direito à moradia deve levar a assegurar ao individuo e sua família um lar, um lugar para os afetos, que representa uma segurança, um porto seguro, refúgio vital para a constituição e construção do indivíduo. É muito mais que um local físico, é imaterial. Um lugar que possibilita o encontro consigo mesmo e os seus, onde há valores, crenças, respeito, e discordâncias. Não há como pensar o Estado democrático e a dignidade da pessoa humana sem a efetivação desse direito.

$\mathrm{O}$ direito à cidade nasce justamente ao direito à moradia. É um direito coletivo, no qual o coletivo, ou seja, todos da cidade são responsáveis pelo processo urbanizatório. É um direito que garante a inclusão. Quando todos têm o direito de participar na construção de nossas cidades, caminha-se para um equilíbrio e uma distribuição mais justa dos ônus e bônus inerentes ao processo aos envolvidos. 
As ocupações irregulares, apesar de suas várias qualidades humanas e espaciais, representam a ausência tanto do direito à moradia quanto do direito à cidade. Caracterizam-se pela falta do título de propriedade, irregularidades nas vias de circulação e do tamanho e forma dos lotes, e a carência de serviços públicos essenciais (como coleta de lixo, rede de esgoto, rede de água, energia elétrica e iluminação pública). Representam também a precarização de direitos pela sua condição de vulnerabilidade e por que os moradores desses locais desprendem maiores recursos para ter acesso a tais direitos.

Por isso surge a regularização fundiária como uma tentativa de assegurar o direito à moradia e à cidade. Alguns instrumentos legislativos foram mencionados, dentre os quais destacam-se, além da Constituição Federal, o Estatuto da Cidade, a Lei da Minha Casa Minha Vida (Lei ${ }^{\circ}$ 11.977/2009) e a Lei da Regularização Fundiária Rural e Urbana (Lei nº 13.465/2017). Mas essas medidas não são suficientes para afastar a gentrificação, que representa, como alguns autores apontam, uma remoção branca e branda, uma retirada pelo mercado de pessoas pobres para acomodar pessoas de posses financeiras. Com a transformação do espaço urbano e a respectiva valorização para o mercado imobiliário, há a dificuldade ou impossibilidade do acesso ou permanência dos pobres nessas áreas, o que acaba gerando a segregação espacial das cidades.

Nesse sentido, percebe-se que, apesar de os direitos à moradia e à cidade estarem tipificados e consagrados, fatores históricos e sociais tornam a realização desses direitos uma tarefa extremamente complexa de se resolver. Mesmo após a previsão legislativa da regularização fundiária, por meio de normas que ampliaram as ferramentas para a Administração Pública regularizar áreas com vulnerabilidade social, as favelas continuam a se multiplicar no Brasil e, quando se realiza a regularização, corre-se o risco de ocorrer a gentrificação. Assim, para além da regularização dessas áreas, há a necessidade de redistribuir as benesses das cidades, isto é, a Administração deve exercer (colocar em prática, ampliar) seu poder de arrecadação e fiscalização para efetivar as políticas de interesse social. Por isso, são necessárias políticas públicas para reaver os benefícios coletivos da cidade apropriados por poucos, para realizar uma espécie de redistribuição dos investimentos realizados pelo Poder Público.

\section{REFERÊNCIAS}

BATALLER, Maria Alba Sargatal. Estudo da Gentrificação. Revista Continentes (UFRRJ), ano 1, n. 1, 2012, p. 9-37, disponível em: https://bit.ly/2SJ4LxR, acesso 11/12/2018.

BRASIL. Ministério das Cidades. Regularização Fundiária Urbana: como aplicar a Lei Federal n 11.977/2009. Ministério das Cidades, Secretaria Nacional de Habitação e Secretaria Nacional de Programas Urbanos. Brasília, 2010, disponível em https://bit.ly/2ruVQo7, acesso em $10 / 12 / 2018$.

CUSTÓDIO, H. B. Estatuto da Cidade e Incompatibilidades Constitucionais, Urbanísticas e Ambientais (Lei n. 10.257, de 10-7-2001, e Medida Provisória n. 2.220, de 4-9-2001). Rev. de

Direitos Difusos, n. 12, p. 357-400, 2002. 
D’AMBROSIO, Daniela. O Direito Fundamental à Moradia Digna. 2013. 107 f. Dissertação (Mestrado em Direito Urbanístico) - Pontifícia Universidade Católica, São Paulo. 2013.

GRAZIANO SOBRINHO, Sergio Francisco; MALINVERNI DA SILVEIRA, Clóvis Eduardo. Meio ambiente urbano, medo e exclusão social: a continuidade entre os processos de gentrificação e a gestão da violência no Brasil. Revista Direito \& Paz, v. 2, n. 37, p. 154-178, dez. 2017. Disponível em: https://bit.ly/2rudNTw, acesso em: 11/12/2018.

HARVEY, David. Direito à Cidade. Trad. Jair Pinheiro. New Left Raview, n. 53, p. 73-89. 2008. Disponível em: https://bit.ly/2Lb2JE3, acesso em: 11/12/2018.

HENRIQUES, Antonio; MEDEIROS, João Bosco. Metodologia Científica na Pesquisa Jurídica. 9. ed. rev. São Paulo: Atlas, 2017.

PIOLI, Maria Sulema M. de Budin; ROSSIN, Antonio Carlos. O Meio Ambiente e a Ocupação Irregular do Espaço Urbano. Revista Brasileira de Ciências Ambientais, n. 3, p. 40-56, abril de 2006.

RANGEL, Helano Márcio Vieira. SILVA, Jacilene Vieira da. O Direito Fundamental à Moradia como Mínimo Existencial. Veredas do Direito, Belo Horizonte, v.6, n.12, p.57-78, Jul.-Dez. 2009.

ROMANELLI, Luiz Claudio. Direito à moradia à luz da gestão democrática. Curitiba: Juruá, 2007.

SOUZA, Sérgio Iglesias Nunes de. Direito à moradia e de habitação: análise comparativa e seu aspecto teórico e prático como os direitos de personalidade. 3. ed., rev., atual e ampl. São Paulo: Revista dos Tribunais, 2013.

WILLIAMSON, Theresa. Regularização Fundiária e Planejamento Urbano nas Favelas Cariocas, Rio On Watch, 19/09/2013. Disponível em: http://rioonwatch.org.br/?p=7436, acesso em: $11 / 12 / 2018$.

Recebido em: 23/04/2019.

Aprovado em: 06/05/2019. 